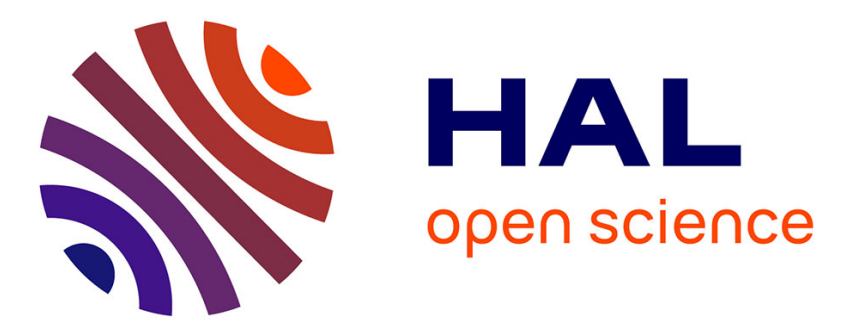

\title{
ULTRAFAST RECOVERY OF ABSORPTION SATURATION IN GaAs / AlGaAs MULTIPLE QUANTUM WELLS
}

D. Hulin, M. Joffre, A. Migus, J. L . Oudar, J . Dubard, F. Alexandre

\section{- To cite this version:}

D. Hulin, M. Joffre, A. Migus, J. L . Oudar, J . Dubard, et al.. ULTRAFAST RECOVERY OF ABSORPTION SATURATION IN GaAs / AlGaAs MULTIPLE QUANTUM WELLS. Journal de Physique Colloques, 1987, 48 (C5), pp.C5-267-C5-270. 10.1051/jphyscol:1987557 。 jpa-00226761

\section{HAL Id: jpa-00226761 https://hal.science/jpa-00226761}

Submitted on 1 Jan 1987

HAL is a multi-disciplinary open access archive for the deposit and dissemination of scientific research documents, whether they are published or not. The documents may come from teaching and research institutions in France or abroad, or from public or private research centers.
L'archive ouverte pluridisciplinaire HAL, est destinée au dépôt et à la diffusion de documents scientifiques de niveau recherche, publiés ou non, émanant des établissements d'enseignement et de recherche français ou étrangers, des laboratoires publics ou privés. 


\title{
ULTRAFAST RECOVERY OF ABSORPTION SATURATION IN GaAS / AIGAAS MULTIPLE QUANTUM WELLS
}

\author{
D. HULIN(1), M. JOFFRE(1), A. MIGUS, J.Lr. OUDAR*, J. DUBARD* and \\ F. ALEXANDRE*
}

Laboratoire d'optique Appliquée, ENSTA, Ecole Polytechnique, F-91120 Palaiseau, France

* Centre National d'Etudes des Télécommunications, 196, Avenue Henri Ravera, F-92220 Bagneux, France

Résumé: La saturation de l'absorption bande à bande produite par une forte densité de porteurs photocréés disparaît rapidement, en une dizaine de picosecondes, dans les structures à puits quantiques multiples à basse température. Ce raccourcissement de la durée de vie des porteurs est dû à l'émission stimulée le long des couches excitées. Les expériences de luminescence confirment cette interprétation.

Abstract: Band to band absorption in multiple quantum well structures at low temperature recovers in tens of picoseconds after its saturation by a large density of photoexcited carriers. Amplification of the spontaneous emission along the excited layers is at the origin of this short lifetime. Luminescence experiments confirm this interpretation.

Multiple Quantum Well Structures (MQWS) offer great promises for applications in optoelectronic devices due to their large optical non-linearities. The onset of the optical property modification has been demonstrated to be in the picosecond range or less depending on the excitation duration. Recently the problem of the recovery time has also been approached. Several attempts have been made in this context to reduce the excited carrier lifetime through non-radiative processes [1,2]. In our studies on GaAs / AlGaAS MQWS's, we have found an unusually fast absorption recovery (within the first 10 ps) in the spectral region above the $n=1$ exciton in the case of a MQW structure excited at low temperature by ultrashort light pulses. Such a fast recovery did not occur in previous studies on bulk GaAs [3] under similar excitation intensities. We present several experimental evidences that this effect is due to the large stimulated recombination rate caused by amplified spontaneous luminescence guided along the MQWS.

The MQWS sample, grown by molecular beam epitaxy, consists of 60 GaAs wells of $75 \AA$ width separated by $\mathrm{Al}, \mathrm{Ga}_{0}$ As barriers of $85 \AA$, sandwiched between two $\mathrm{AlGaAs}$ layers each of $1 \mathrm{\mu m}$ thickness. For transmission experiments, the GaAs substrate was removed by selective etching on a surface of about $1 \mathrm{~mm}^{2}$. After this preparation, the MQWS remains protected by the two AlGaAs layers, transparent at the wavelengths of interest. The good quality of the sample is confirmed by well defined excitonic structures at $15 \mathrm{~K}$ and room temperature.

We have performed time-resolved transmission experiments using the classical pump and probe scheme and time-resolved luminescence measurements. In both cases, the primary source is the output of a CPM dye laser amplified through four stages of dyes pumped by a frequency-doubled $\mathrm{Nd}-\mathrm{Yag}$ laser at $10 \mathrm{~Hz}$ [4]. These pulses have a duration of $100 \mathrm{fs}$ with an energy of $0.3 \mathrm{~mJ}$ at $620 \mathrm{~nm}$. The beam is then split in two parts, one of the optical paths travelling through a variable optical path. In this pump-probe scheme, a wavelength continuum of the same duration as the initial pulse is generated in each path by focusing the beam into different water cells. The pump wavelength is selected with an interferential filter centered at $690 \mathrm{~nm}$, the energy per pulse around $0.5 \mu \mathrm{J}$. This excitation beam is focused on a $0.1 \mathrm{~mm}^{2}$ area leading to an energy density of $0.5 \mathrm{~mJ} / \mathrm{cm}^{2}$. The other continuum is filtered out and attenuated to be much less intense than the excitation.

\footnotetext{
(1) Also at groupe de Physique des Solides de 1'Ecole Normale Supérieure. T-23, 2, Place Jussieu, F-75230 Paris Cedex 05, France
} 
The luminescence experiments have been performed by using an optical gate driven by the optical Kerr effect [5]. The luminescence signal is sent through two crossed polarizers with a cell filled of $\mathrm{CS}_{2}$ in-between and is after that collected into the spectrometer. In absence of any perfurbation, the $\mathrm{CS}_{2}$ liquid is isotropic and no signal passes through the crossed polarizers. An anisotropy can be induced by shining the liquid by part of the pump beam at $620 \mathrm{~nm}$. This effect comes from the orientation of the molecules towards the electromagnetic field (optical Kerr effect). The induced anisotropy leads to a rotation of the signal polarization: the component parallel to the second polarizer is then non-null and can be detected. By varying the delay between the pulse at $620 \mathrm{~nm}$ on the liquid cell and and the exciting pulse on the sample, we collect directly on the multichannel analyzer the time-resolved spectral dependence of the luminescence signal. The zero delay is determined by the detection of the exciting beam scattered from the sample surface. The time resolution depends both on the medium relaxation constant and on the velocity mismatch between $620 \mathrm{~nm}$ and $800 \mathrm{~nm}$ in $\mathrm{CS}_{2}$ all along the cell. The relaxation of $\mathrm{CS}_{2}$ by itself gives an opening time of about $0.6 \mathrm{ps}$ but the dispertion in the $1 \mathrm{~cm}$ long cell leads to a time resolution of $2 \mathrm{ps}$. This can be improved by using either a shorter cell or a liquid such as benzene [5] but at the expense of a lowering of the gate efficiency ( for a $1 \mathrm{~cm}$ cell of $\mathrm{CS}_{2}$ the opening efficiency ranges between $10 \%$ and $30 \%$ ).

The absorption spectra display very different behaviors at high and low temperatures (fig 1-a and $1-b$ ). In both cases, the saturation of the excitonic absorption is almost fully achieved within 1 ps after excitation. At room temperature the saturation of the band to band absorption is significant and is almost stable during the first hundred picoseconds. At low temperatures $(T=15 K)$ the absorption saturation is quite similar just after the creation of the electrons and the holes by the $690 \mathrm{~nm}$ pump pulse. However, in the following times the behavior is rather different since after 20 ps the band to band absorption has almost completely recovered its initial value while only excitons remain bleached.

The induced changes in the band to band absorption magnitude can be directly related to the electron-hole distribution. With a simple model [6] the data can be analyzed giving the carrier density and temperature at each delay. By assuming an equal temperature for the electrons and the holes, we find that at room temperature the carrier density is almost constant (less than $20 \%$ change) on our time scale while a rapid cooling of the electronic temperature (initially $1100 \mathrm{~K}$ ) occurs toward the lattice temperature. At low lattice temperature, the initial carrier density is also $10^{12} \mathrm{~cm}^{-2}$ but drops by a factor 3 in 15ps. The cooling process is slightly less efficient. These differences in the carrier density evolution cannot be explained only by taking into account the usual bimolecular recombination, which would lead to a disappearence of the carriers on a nanosecond time scale. Surface or defect annihilations can be ruled out. We attribute therefore such a short recombination time at low temperature to the appearence of strong stimulated emission. Indeed in our experimental conditions (relatively high carrier densities at low temperature) a substantial gain can developp. The spot diameter is typically $300 \mu \mathrm{m}$; hence the luminescence guided along the MQWS layer can undergo substantial amplification and therefore considerably increase the recombination rate through stimulated emission. This mechanism is less effective when the sample is at $300 \mathrm{~K}$ due to the higher electronic temperature.

To confirm the role of stimulated emission, we have observed the luminescence emitted by the sample edge while the excitation beam was focused on the front surface. In a first experiment, the time-integrated signal was monitored as a function of the excitation length for a fixed excitation density. The time-integratd spectra displayed two distinct features: a line at $790 \mathrm{~nm}$ originating from the exciton annihilation and a band at $794.5 \mathrm{~nm}$ corresponding to the plasma emission. This emission is at lower energy than the excitonic transition due to the band gap renormalization. By increasing the length of the excited area from a reduced spot near the edge of observation to a strip of $3 \mathrm{~mm}$ length, the two lines behaved very differently. The exciton luminescence was almost constant in intensity and shape. On the contrary, the plasma emission increased exponentially with the excitation length, a clear evidence of amplification along the MQWS layers. The gain of $10 \mathrm{~cm}^{-1}$ is quite low but corresponds to a smaller excitation density necessitated to realize the beam geometry. 
a

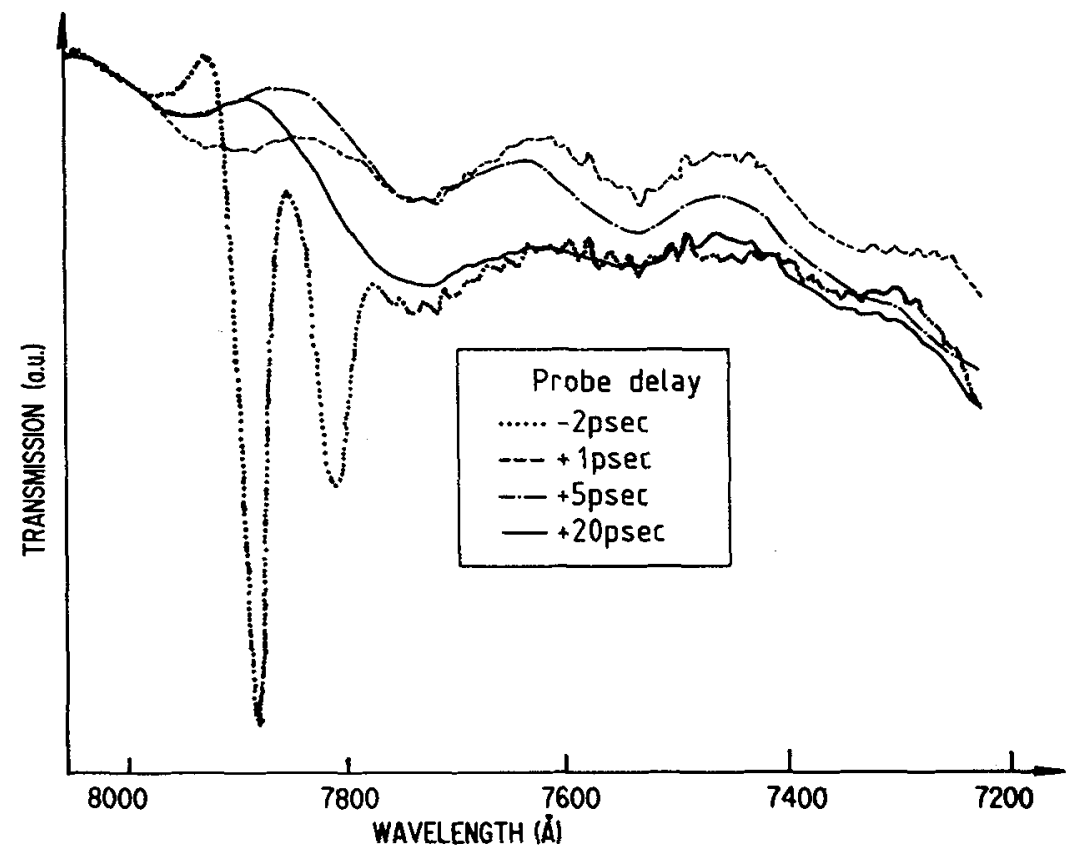

b

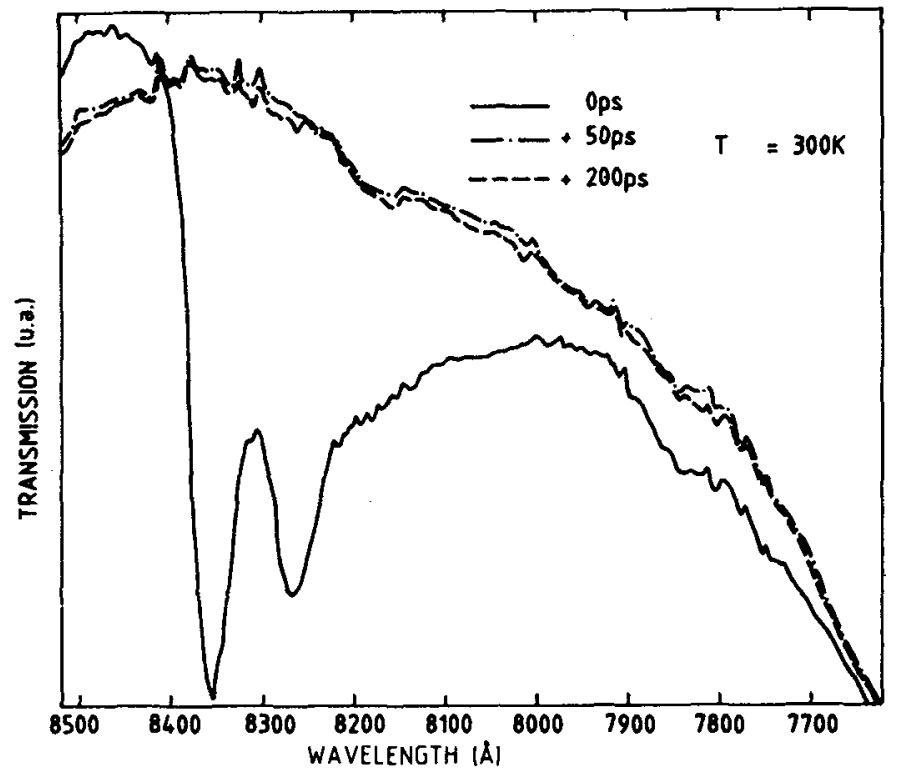

Figure 1 : Transmission spectra of the sample for various delays between pump and probe. Sample temperature is (a) $\mathrm{T}=15 \mathrm{~K}$ and (b) $\mathrm{T}=300 \mathrm{~K}$. 


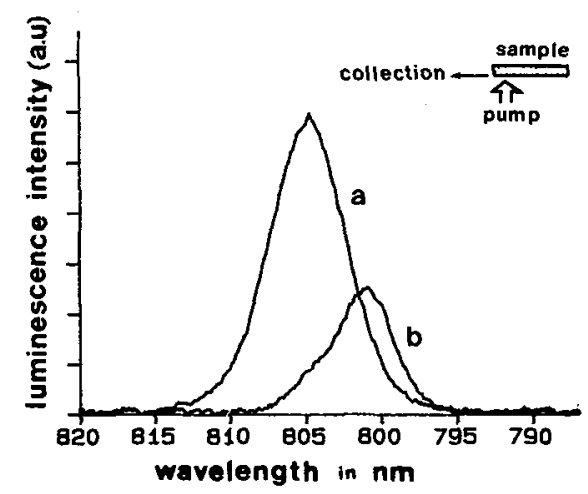

Figure2 : Time-resolved spectra of the luminescence collected at the edge of the MQWS at $15 \mathrm{~K}$ for two differents delays after the pump excitation (12 ps for (a) and 24 ps for (b)).

The time-resolved spectra of the edge emission are recorded in the same excitation conditions as for the pump-probe experiments. Therefore the spectra are strongly dominated by the plasma amplified emission, the exciton luminescence being negligeable. The signal exhibits a first maximum before decreasing to zero, followed by a second maximum, then a third one with a smaller intensity and so on. By moving the position of the exciting spot we have checked that these different light packets (also seen as spikes with a streak camera) correspond to multiple reflections on the sample edges. The light is emitted only once but travel different optical paths inside the sample before the collection at the edge. The amplified emission does not appear instantaneously after excitation since the gain can developp only after the cooling of the excited carriers. At a delay of $12 \mathrm{ps}$ (fig 2) the low energy luminescence edge is at $812 \mathrm{~nm}$, corresponding to a band gap renormalization of $50 \mathrm{meV}$. At $24 \mathrm{ps}$, the edge is at $806 \mathrm{~nm}$ implying therefore a band gap renormalization of $38.6 \mathrm{meV}$. Following G. Tränkle et al. [7], the 2D band-gap renormalization depends on the density following a $\mathrm{n}_{2 \mathrm{D}}{ }^{1 / 3}$ law. Starting with a carrier density of a few $10^{12} \mathrm{~cm}^{-2}$, the evolution of the band gap renormalization corresponds to a decrease of the density by a factor 2.2 which is consistent with the value deduced from the absorption experiments.

In conclusion the time-resolved absorption and luminescence experiments confirm the importance of the stimulated emission along the MQWS layers in the reduction of the carrier lifetime. This fast recovery of the band to band absorption for a sample at low temperature may have some implications for the use of such structures in optical devices.

\section{REFERENCES}

1- Y. Silberberg, P.W. Smith, D.A.B. Miller, B. Tell, A.C. Gossard and W. Wiegmann, Appl. Phys. Lett. 46, 701 (1985)

2- Y.H. Lee, M. Warren, G.R. Olbright, H.M. Gibbs, N. Peyghambarian, T. Venkatesen, J.S. Smith and A. Yariv, Appl. Phys. Lett. 48, 754 (1986)

3- J.L. Oudar, I. Abram, A. Migus, D. Hulin and J. Etchepare, J. of Lum. 30, 340 (1985)

4- A. Migus, A. Antonetti, J. Etchepare, D. Hulin and A. Orszag, J. Opt. Soc. Am. B2, 584 (1985)

5- D. Hulin, J. Etchepare, A. Antonetti, L.L. Chase, G. Grillon, A. Migus and A. Mysyrowicz, Appl. Phys. Lett. 45, 993 (1984)

6- J. Dubard, J.L. Oudar, F. Alexandre, D. Hulin and A. Orszag, Appl. Phys. Lett. 50, $821(1987)$

7- G. Tränkle, H. Leier, A. Forchel, H. Haug, C. Hell and G. Weinmann, Phys. Rev. Lett. 58, 419 (1987) and references therein. 